02

\title{
Калибровка температуры по спектрам флуоресценции допированного эрбием свинцово-фторидного стекла
}

\author{
() М.А. Ходасевич ${ }^{1}$, В.А. Асеев ${ }^{2}$, Ю.А. Варакса ${ }^{1}$, Д.А. Борисевич ${ }^{1}$ \\ ${ }^{1}$ Институт фозики НАН Беларуси, \\ 220072 Минск, Беларусь \\ ${ }^{2}$ Университет ИТМО, \\ 197101 Санкт-Петербург, Россия \\ e-mail m.khodasevich@ifanbel.bas-net.by
}

Поступила в редакцию 02.11.2018 г.

В окончательной редакции 02.11.2018 г.

Принята к публикации 12.11.2018 г.

К спектрам зеленой флуоресценции эрбия в свинцово-фторидном стекле, допированном 0.5 то1.\% эрбия и 10 mol.\% иттербия, применены многопараметрические методы калибровки температуры в диапазоне от 299 до 423 К. Показано, что среди рассмотренных методов регрессия на латентные структуры по комбинации движущихся спектральных окон характеризуется наименьшей величиной $(0.2$ К) среднеквадратичной ошибки предсказания температуры по проверочной выборке. Искусственная нейронная сеть с использованием двух главных компонент в качестве входных переменных, широкополосная регрессия на латентные структуры, искусственная нейронная сеть с использованием всех спектральных отсчетов в качестве входных переменных и регрессия на главные компоненты уступают по точности калибровки температуры.

DOI: $10.21883 /$ OS.2019.03.47369.317-18

В последние годы калибровка по спектральным данным востребована в различных областях науки и производства: экологии [1] и медицине [2], фармацевтике [3] и химической промышленности [4], сельском хозяйстве [5], пищевой [6] и винодельческой [7] промышленности, биоэнергетике [8] и других. Калибровка искомого параметра исследуемого с использованием спектральных методов объекта заключается в замене прямых измерений этого параметра на измерения спектров с последующей обработкой полученной информации.

Рассмотрим калибровку температуры по спектрам флуоресценции эрбия в свинцово-фторидном стекле, допированном $0.5 \mathrm{~mol} . \%$ эрбия и 10 мол.\% иттербия. Ранее [9] нами было показано, что применение регрессии на латентные структуры (PLSR - projection to latent structures regression) [10] к температурной зависимости спектров флуоресценции эрбия позволяет достичь лучшей точности калибровки температуры по сравнению с широко распространенным методом отношения интенсивностей флуоресценции с двух температурно связанных уровней [11]. В настоящей работе мы используем три многопараметрических метода регрессию на главные компоненты (PCR - principal component regression) [12], регрессию на латентные структуры и искусственную нейронную сеть (ANN artificial neural network) [13] - для определения качества калибровки с помощью сравнения среднеквадратичной ошибки RMSEP (root-mean-squared error of prediction) предсказания величины температуры по проверочной выборке.

Возбуждение эрбиевого стекла осуществлялось неполяризованным излучением лазерного диода ML-151
(„Милон“, Россия) мощностью $2.25 \mathrm{~W}$ с максимумом спектра около $970 \mathrm{~nm}$. Спектры флуоресценции регистрировались в диапазоне 190-1100 nm спектрометром S100 („Солар ЛС“, Беларусь) со средним разрешением $1 \mathrm{~nm}$ в температурном диапазоне от 299 до $423 \mathrm{~K}$ с шагом 2 К. Для построения многопараметрических моделей использовался спектральный диапазон 500-560 nm, в который попадает зеленая ап-конверсионная флуоресценция эрбия и который содержит 227 отсчетов (спектральный шаг менее $0.3 \mathrm{~nm}$ ). Температура образца изменялась и контролировалась с точностью 0.1 К с помощью печи PV10 („Coversion Ltd“, Великобритания) и температурного контроллера TS-200 („Thorlabs“, США).

К зарегистрированным спектрам флуоресценции было применено центрирование как способ предобработки данных, после чего они были объединены в матрицу размерами $63 \times 227$, где $63-$ количество спектров. Проведенный с помощью метода главных компонент [12] анализ температурной зависимости счетов в первую главную компоненту, описывающую 96.5\% суммарной объясненной дисперсии данных, показал незначительные отклонения этой зависимости от линейной при температурах 301, 313, 339, 349, 363, 269, 373, 391 К. Поскольку указанные отклонения невелики, в дальнейшем мы полагаем, что выбросы, требующие удаления из выборки, в рассматриваемом наборе спектров отсутствуют.

Первым примененным для калибровки температуры многопараметрическим методом является построение ANN. Так как методы выбора спектральных переменных [14-16] на первом этапе работы не применялись, то в качестве входных переменных использовались все имеющиеся 227 отсчетов, нормированные так, чтобы 
их значения на каждой длине волны заключались в пределах отрезка $[-1,1]$. Набор проведенных измерений был разделен на три выборки: обучающую $(\approx 70 \%$ от общего количества или 45 спектров), выборку для проведения валидации калибровочной модели $(\approx 15 \%$ или 10 спектров) и проверочную (9 спектров). Спектры в выборки для валидации $(301,313,327,341,353,367$, $381,393,407$ и 414 К) и проверки $(305,317,331,345$, $357,371,385,397$ и 411 К) отбирались равномерно и поочередно по мере роста температуры. Целью такого отбора являлся более равномерный охват диапазона изменения температуры обеими выборками.

ANN состояла из одного скрытого слоя (от 2 до 20 нейронов) с активационной функцией нейрона типа гиперболического тангенса и выходного нейрона с линейной переходной функцией. При обучении сети решалась задача подбора весов и смещений так, чтобы минимизировать значение целевой функции - величину среднеквадратичной ошибки калибровки. На первом этапе для подбора параметров ANN использовался алгоритм Левенберга-Марквардта [17]. По результатам валидации построенной модели обучение сети останавливалось при достижении заданного граничного значения любым из следующих параметров: величиной градиента целевой функции; количеством последовательных итераций, при которых среднеквадратичная ошибка калибровки не убывала; значением целевой функции; количеством итераций. Для предотвращения переобучения на втором этапе моделирования применялась байесовская регуляризация [17], минимизирующая линейную комбинацию ошибок и весов. Параметром качества многопараметрической модели являлась среднеквадратичная ошибка RMSEP калибровки температуры по проверочной выборке. На рис. 1 представлена монотонно убывающая зависимость RMSEP от количества нейронов в скрытом слое. При 20 нейронах модель характеризуется среднеквадратичной ошибкой $0.33 \mathrm{~K}$.

Для определения эффективности калибровки с помощью построения ANN была проведена калибровка температуры также с помощью PCR и PLSR. B методе PCR в многомерном пространстве исходных спектров выделяется маломерное пространство главных компонент таким образом, чтобы минимизировать влияние мультиколлинеарности спектров и присутствующего в них шума. При таком проецировании не учитывается соответствующее спектру значение температуры. В методе PLSR кроме спектров в многомерное пространство данных входит и вектор значений температуры. PLSR находит маломерное пространство так называемых латентных переменных, проекции матрицы спектров и вектора значений температуры в которое имеют максимальную ковариацию.

Как и для модели $\mathrm{ANN}$, построенной по всем измеренным спектральным отсчетам, параметром качества предсказания температуры методами PCR и PLSR является среднеквадратичная ошибка RMSEP. Значения этой величины вместе со среднеквадратичной ошибкой

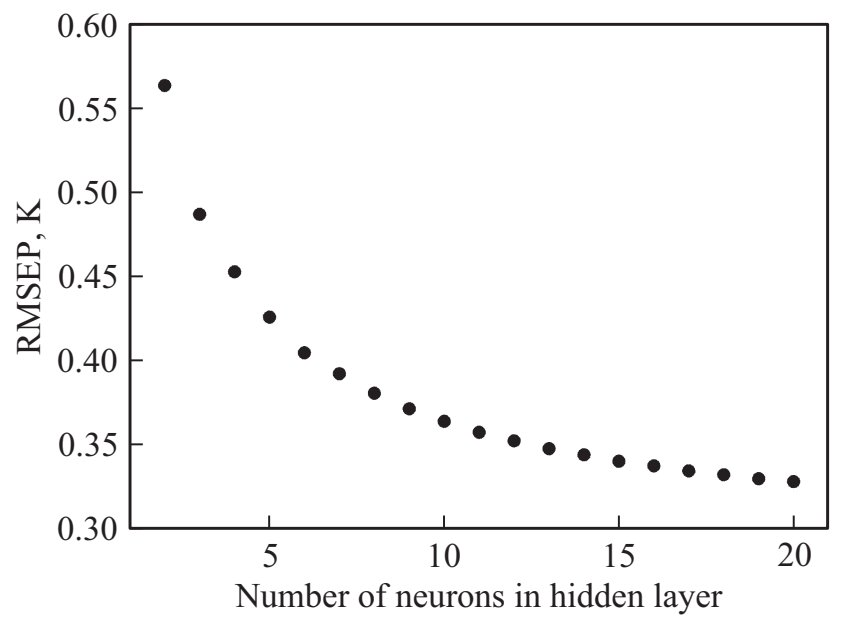

Рис. 1. Зависимость среднеквадратичной ошибки RMSEP калибровки температуры с помощью ANN от количества нейронов в скрытом слое.

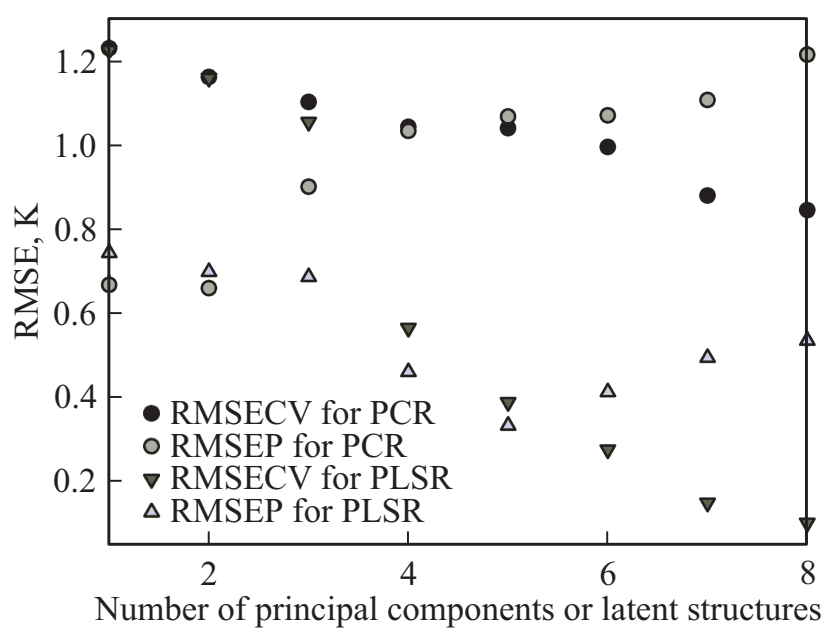

Рис. 2. Зависимость среднеквадратичной ошибки калибровки температуры по обучающей (RMSECV) и проверочной (RMSEP) выборкам с помощью PCR и PLSR.

RMSECV (root-mean-squared error of cross validation) калибровки по обучающей выборке при проведении кросс-валидации представлены на рис. 2 для обоих видов применяемой регрессии.

Для одно- и двумерных пространств величины RMSECV для PCR и PLSR практически совпадают. Это показывает, что учет вектора значений температуры в рассматриваемом случае существен только начиная с третьей латентной переменной. Зависимости величины RMSECV от количества переменных в моделях являются монотонно убывающими, что подтверждает неприменимость этих параметров в качестве критериев для понижения размерности пространства представления спектральных данных. Минимальное значение величины RMSEP для PCR соответствует двум главным компонентам, а для PLSR - пяти латентным структурам. 


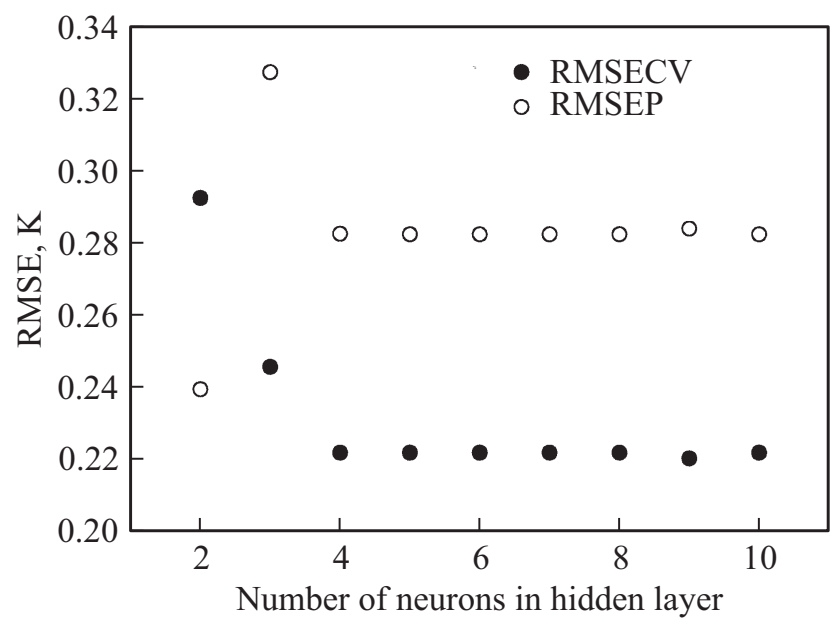

Рис. 3. Зависимость RMSECV и RMSEP при калибровке методом ANN-PCA.

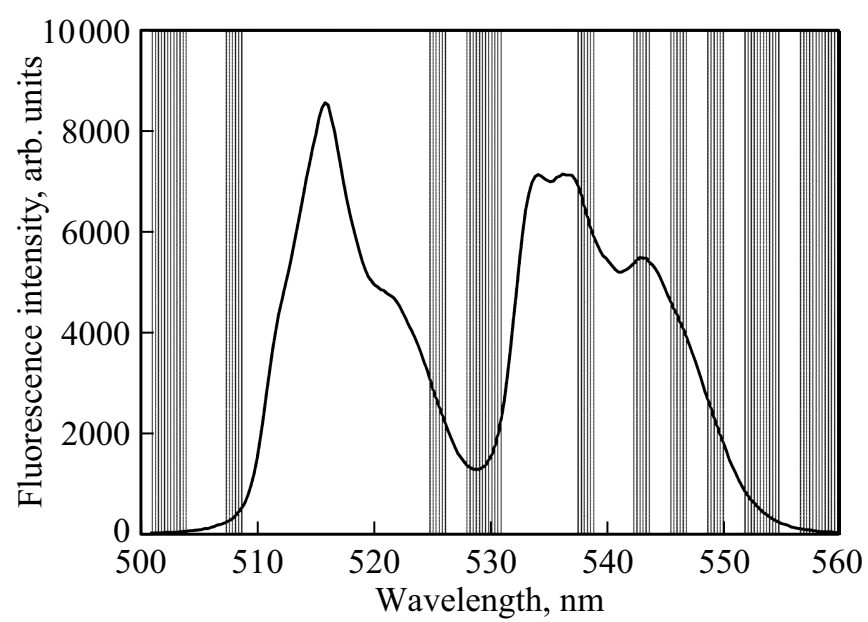

Рис. 4. Спектр флуоресценции исследуемого образца при 299 К и спектральные интервалы, предсказание температуры по которым методом scmwiPLSR характеризуется минимальной величиной RMSEP.

Поэтому калибровка температуры оптимальна в двумерном пространстве главных компонент и пятимерном пространстве латентных структур. Среднеквадратичная ошибка калибровки по проверочной выборке для PCR равна 0.66 K, а для PLSR - 0.33К. Таким образом, калибровка по широкополосным спектрам с помощью линейного метода PLSR в пространстве латентных структур оптимальной размерности и нелинейного метода ANN с 20 нейронами в скрытом слое характеризуется в рассматриваемом случае приблизительно одинаковой среднеквадратичной ошибкой.

Так как возможности метода ANN явно не ограничиваются 20 нейронами в скрытом слое (рис. 1), рассмотрим объединение методов PCA и ANN, когда в качестве входных переменных ANN используются не спектральные отсчеты, а главные переменные спектров флуоресценции. Результаты поиска оптимального
Минимальные среднеквадратичные ошибки предсказания температуры при использовании различных методов калибровки температуры по спектрам флуоресценции эрбия в свинцовофторидном стекле, допированном $0.5 \mathrm{~mol} . \%$ эрбия и $10 \mathrm{~mol} . \%$ иттербия

\begin{tabular}{c|c|c|c|c|c}
\hline Метод & ANN & PCR & PLSR & ANN-PCA & scmwiPLSR \\
\hline RMSEP, К & 0.33 & 0.66 & 0.33 & 0.28 & 0.20
\end{tabular}

количества нейронов в скрытом слое ANN-PCA представлены на рис. 3. Видно, что уже при 4 нейронах достигается величина RMSEP $=0.28$ К, которая практически не меняется при увеличении количества нейронов. Таким образом, уменьшение мультиколлинеарности спектральных переменных с помощью применения РСА позволило улучшить точность калибровки температуры методом ANN-PCA на 15\% по сравнению с точностью метода ANN по всему рассматриваемому спектральному диапазону.

Для увеличения точности калибровки температуры с помощью PLSR мы применяем метод выбора спектральных переменных путем поиска комбинации движущихся окон (интервалов) (scmwiPLSR - searching combination of moving windows for interval PLSR) [16], являющийся одним из эффективных методов интервального выбора переменных. Под интервалом в многопараметрическом спектральном анализе подразумевают несколько соседних длин волн, измерения на которых коррелированы. Среди интервальных методов выбора переменных на основе PLSR можно выделить iPLSR (interval PLSR) [14], когда диапазон измерений спектра делится на некоторое количество неперекрывающихся интервалов, по каждому из которых строится отдельная модель; fiPLSR (forward iPLSR) и biPLSR (backward iPLSR) [18], в которых спектральные интервалы последовательно объединяются или по одному изымаются из полного диапазона измерений; mwiPLSR (moving window iPLSR) [15], в котором интервал может изменять размер и сдвигаться по спектру, и другие модификации этих методов.

Примененная нами модификация метода scmwiPLSR [19] может быть описана следующим образом. При построении регрессии по 5 латентным структурам используем минимальную ширину спектрального окна, которая составляет 6 длин волн. Положение первого спектрального окна определяется минимальной величиной RMSEP для моделей, построенных по непересекающимся интервалам минимальной ширины, и фиксируется. Следующее окно последовательно сдвигается в пределах всего спектрального диапазона измерений и объединяется с первым также при выполнении условия минимальности величины RMSEP для модели, построенной по объединенному множеству спектральных отсчетов. Процедура продолжается до включения в модель полного диапазона измерений, так как идет поиск глобального минимума зависимости величины RMSEP 
от количества учитываемых в модели спектральных окон. В рассматриваемом случае глобальный минимум соответствует 14 спектральным окнам, представленным вместе со спектром флуоресценции на рис. 4. Величина RMSEP для модели PLSR по выделенным на рис. 484 спектральным отсчетам составляет $0.20 \mathrm{~K}$.

В таблице представлены величины среднеквадратичной ошибки предсказания температуры по проверочной выборке для всех примененных нами в настоящей работе методов.

Итак, на примере зеленой флуоресценции эрбия в свинцово-фторидном стекле, допированном $0.5 \mathrm{~mol} \%$ эрбия и $10 \mathrm{~mol} \%$ иттербия, проведено сравнение точности методов многопараметрической калибровки температуры и рассмотрены некоторые возможности понижения среднеквадратичной ошибки предсказания температуры по проверочной выборке. Показана эффективность понижения количества входных переменных для построения искусственной нейронной сети методом главных компонент. Лучший результат по величине ошибки калибровки температуры получен с помощью применения регрессии на латентные структуры по комбинации движущихся окон, когда из 227 длин волн в многопараметрическую модель были отобраны только 84.

Исследование выполнено при поддержке Белорусского республиканского фонда фундаментальных исследований (проект Ф18Р-238) и Российского фонда фундаментальных исследований (проект 18-58-00043).

\section{Список литературы}

[1] Xu S., Zhao Y., Wang M., Shi X. // Geoderma. 2018. V. 310. P. 29-43. doi 10.1016/j.geoderma.2017.09.013

[2] Goodarzi M., Sharma S., Ramon H., Saeys W. // TrAC Trends in Analytical Chemistry. 2015. V. 67. P. 147. doi 10.1016/j.trac.2014.12.005

[3] Da Silva V.H., da Silva J.J., Pereira C.F. // J. Pharmaceutical and Biomedical Analysis. 2017. V. 134. P. 287-294. doi 10.1016/j.jpba.2016.11.036

[4] Sulub Y., DeRudder J. // Polymer Testing. 2013. V. 32. P. 802. doi 10.1016/j.polymertesting.2013.03.008

[5] Pezzei C.K., Schönbichler S.A., Kirchler C.G., Schmelzer J., Hussain S., Huck-Pezzei V.A., Popp M., Krolitzek J., Bonn G.K., Huck C.W. // Talanta. 2017. V. 169. P. 70. doi 10.1016/j.talanta.2017.03.067

[6] Siriphollakul P., Nakano K., Kanlayanar S., Ohashi S., Sakai R., Rittiron R., Maniwara P. // LWT - Food Science and Technology. 2017. V. 79. P. 70. doi 10.1016/j.lwt.2017.01.014

[7] Ходасевич М.А., Синицын Г.В., Скорбанова Е.А., Роговая М.В., Камбур Е.И., Асеев В.А. // Опт. и спектр. 2016. Т. 120. С. 1046.; Khodasevich M.A., Sinitsyn G.V., Skorbanova E.A., Rogovaya M.V., Kambur E.I., Aseev V.A. // Opt. Spectrosc. 2016. V. 120. P. 978. doi 10.1134/S0030400X16050155

[8] Skvaril J., Kyprianidis K.G., Dahlquist E. // Applied Spectroscopy Reviews. 2017. V. 52. P. 675. doi $10.1080 / 05704928.2017 .1289471$
[9] Асеев В.А., Варакса Ю.А., Колобкова Е.В., Синицын Г.В., Ходасевич М.A. // Опт. и спектр. 2015. Т. 118. С. 760; Aseev V.A., Varaksa Yu.A., Kolobkova E.V., Sinitsyn G.V., Khodasevich M.A. // Opt. Spectrosc. 2015. V. 118. P. 727. doi 10.1134/S0030400X15050033

[10] Geladi P., Kowalski B. // Analyt. Chim. Acta. 1986. V. 185. P. 1. doi 10.1016/0003-2670(86)80028-9

[11] Wade S.A., Collins S.F., Baxter G.W. // J. Appl. Phys. 2003. V. 94. P. 4743. doi 10.1063/1.1606526

[12] Esbensen K.H., Geladi P. // Comprehensive Chemometrics. 2009. V. 2. P. 211. doi 10.1016/B978-044452701-1.00043-0

[13] Haykin S. Neural Networks: A Comprehensive Foundation. Prentice Hall, 1999. 842 p.

[14] Norgaard L., Saudland A., Wagner J., Nielsen J.P., Munck L., Engelsen S.B. // Appl. Spectr. 2000. V. 54. P. 413. doi 10.1366/0003702001949500

[15] Jiang J.-H., Berry R.J., Siesler H.W., Ozaki Y. // Anal. Chem. 2002. V. 74. P. 3555. doi 10.1021/ac011177u

[16] Du Y.P., Liang Y.Z., Jiang J.H., Berry R.J., Ozaki Y. // Anal. Chim. Acta. 2004. V. 501. P. 183. doi 10.1016/j.aca.2003.09.041

[17] Гилл Ф., Мюррей У., Райт М. Практическая оптимизация. М.: Мир, 1985. 509 c.

[18] Zou X., Zhao J., Li Y. // Vibr. Spectr. 2007. V. 44. P. 220. doi 10.1016/j.vibspec.2006.11.005

[19] Khodasevich M.A., Aseev V.A. // Opt. Spectrosc. 2018. V. 124. P. 748. doi 10.1134/S0030400X18050089 